\title{
Legislação global sobre inteligência artificial: uma análise crítica sobre o papel da unesco
}

\author{
Global regulatory instrument on artificial intelligence: a critical analysis on the role \\ of unesco
}

\author{
José Alberto Antunes de Miranda \\ Liziane Menezes de Souza**
}

\section{Resumo}

Ante a expansão global das discussões voltadas à necessidade de definição de boas práticas para desenvolvimento e uso da inteligência artificial, progrediram os esforços, em ambiente internacional, para elaboração de regras globais relativas à ética e a legalidade da utilização de tecnologias inteligentes. Diante deste cenário, importa analisar de que maneira as discussões atuais têm se desenvolvido para a inclusão das argumentações e contribuições trazidas pelos Estados-Nação não situados em local de hegemonia, nas narrativas voltadas à inteligência artificial e ao desenvolvimento das legislações protecionistas de dados pessoais, como aqueles do sul global. Questionam-se quais são as possibilidades e os obstáculos postos diante da Organização das Nações Unidas, para uma atuação efetiva que busque promover o debate multicultural e pluralista para desenvolvimento de regras globais voltadas ao uso ético da inteligência artificial. Dessa forma, a partir de uma revisão bibliográfica, e através do método de abordagem dialético, o estudo demonstrará quais são as problemáticas e os benefícios postos pela Legislação Global de Inteligência Artificial, avaliando qual é o papel desempenhado pela UNESCO e quais são os impactos e efeitos práticos da deliberação em construção, consistente em um rol de recomendações de origem extraconvencional. Conclui-se, portanto, que o rol de recomendações apresenta efeitos jurídicos indiretos e, além disso, potencializa a legitimação de ações de organizações e comunidades do sistema internacional no sentido de proteção de direitos humanos.

Palavras-chave: Inteligência artificial. Direito Internacional. UNESCO. Multiculturalismo. Pluralismo.

\section{Abstract}

Given the global expansion of discussions aimed at the need to define good practices for the development and use of artificial intelligence, efforts have progressed, in an international environment, to develop global rules related to the ethics and legality of the use of intelligent technologies. Given this scenario, it is relevant to analyze how the current discussions have developed to include the arguments and contributions brought by the Nation-States not situated in a place of hegemony in the narratives aimed at artificial intelligence and the development of protectionist legislation on personal data, as those in the global south. It questioned the possibilities and obstacles posed before the United Nations for effective action that seeks to promote multicultural and pluralist debate for the development of the global rules aimed at the ethical use of artificial intelligence. Based on a bibliographic review, through the dialectical method, the study will demonstrate the problems and benefits posed by the Global Artificial Intelligence Legislation, assessing what is the role played by UNESCO and what are the impacts and practical effects of the deliberation under construction, consisting of a list of recommendations of nonconventional origin. It concluded that the list of recommendations has indirect legal effects and, in addition, improves the legitimacy of actions by organizations and communities in the international system in the sense of protecting human rights.

Keywords: Artificial intelligence. International right. UNESCO. Multiculturalism. Pluralism.

Doutor em Estudos Estratégicos Internacionais pela UFRGS (2012). Mestre em Relações Internacionais pela Universidade Federal do Rio Grande do Sul (2004). Especialista em Integração e Mercosul pela UFRGS (1999). Graduado em Direito pela Universidade do Vale do Rio dos Sinos (1996). Assessor de Assuntos Interinstitucionais e Internacionais e professor permanente do Programa de Pós-graduação em Direito e Sociedade além de integrar o corpo docente do Curso de Relações Internacionais da Universidade La Salle. Professor visitante ilustre da Universidade Católica de Trujillo - Peru. E-mail: antunes@unilasalle.edu.br

Mestranda em Direito e Sociedade pela Universidade La Salle. Pós-Graduada em Ensino de Filosofia pela Universidade Federal de Pelotas - UFPel. Bacharel em Direito pela Universidade de Cruz Alta (UNICRUZ). Mobilidade acadêmica na Universidade de Coimbra - PT (UC). Membra do Comitê Jurídico da Associação Nacional de Profissionais de Privacidade de Dados - ANPPD®. Membrada WOMCY/LATAM Women in Cybersecurity. Pesquisadora do Grupo de Pesquisa Jurídica em Cidadania, Democracia e Direitos Humanos - GPJUR (UNICRUZ) e do Grupo de Pesquisa Pluralismo e Direitos Humanos: diálogos culturais transfronteiriços (Unilasalle). Advogada. E-mail: liizianems@gmail. com 


\section{Introdução}

Com o aumento acelerado das discussões acerca da necessidade de desenvolvimento de garantias que tornem efetivo o gozo do direito à proteção de dados pessoais e, também, das maneiras através das quais serão desenvolvidas as ferramentas judiciais que se utilizam da inteligência artificial em tempos de tecnologia avançada, pensar sobre sua adequabilidade legal e sobre as respectivas boas práticas para seu uso é imprescindível. Trata-se de reflexão e investigação essencial para a própria manutenção da inteligência artificial dentro dos limites impostos pelo Estado de Direito e, ademais, em situação de consonância com os interesses protecionistas de direitos fundamentais em sentido global.

Ao se notar que estão em andamento, neste momento, esforços no sentido de promover discussões de abrangência internacional visando o desenvolvimento de recomendações de boas práticas para o uso da inteligência artificial pautadas na pluralidade, o presente artigo científico se propõe a averiguar: qual a situação atual do debate, quais os meios e ferramentas utilizadas para desenvolvimento de regras e/ou orientações e, bem assim, avaliar a existência ou não de força vinculante atrelada a este instrumento; além da pretensão de mensurar o papel da Organização das Nações Unidas para a Educação, a Ciência e a Cultura (UNESCO) frente ao tema.

Com a recente entrada em vigência de leis protecionistas de dados pessoais em inúmeros Estados-Nação e, até mesmo, em sede de união econômica, a saber, no próprio Brasil, através da Lei Geral de Proteção de Dados (Lei $n^{\circ} 13.709 / 18$ ) e na União Europeia, por intermédio do Regulamento Geral sobre a Proteção de Dados $n^{\circ}$ 2016/679 (General Data Protection Regulation), muitos questionamentos vinculam a proteção de dados pessoais ao uso legal da inteligência artificial ao redor do mundo. Questiona-se, neste estudo, quais são as possibilidades e os obstáculos postos diante da UNESCO para uma atuação efetiva que busque promover o debate multicultural e pluralista para desenvolvimento de regras globais para o bom uso da inteligência artificial.

Importa que se analise, também sob a ótica das epistemologias do sul', de que maneira podem os EstadosNação, situados à margem da polarização de teorias sobre o tema, efetivamente, participar e desenvolver argumentações e ações que lhes confiram a possibilidade de atendimento de seus interesses durante a construção de regras de abrangência internacional - ainda que estas, eventualmente, não possuam força normativa ou vinculante.

A presente pesquisa justifica-se, teoricamente, pelo caráter questionador que a teoria da contra-hegemonia voltada às epistemologias do sul oferece ao Direito. Pretende-se abordar questões voltadas às formas de utilização da inteligência artificial, tanto no que se refere à sua adequabilidade a um Estado de Direito, quanto à necessidade de definições éticas para sua utilização. Isso, de maneira a analisar a forma como os Estados-Nação realizam, atualmente, o tratamento de dados pessoais e a implementação de ferramentas inteligentes. Importa verificar, ainda, eventuais situações de exposição e violação de dados pessoais; e, quiçá, de transgressão de direitos fundamentais inerentes à condição humana.

Busca-se avaliar se os debates, acerca da produção de regras e recomendações voltadas às boas práticas de definições de atuação ética para o uso da inteligência artificial, são suficientemente abrangentes a ponto de incluir nações que não se encontram em situação de hegemonia no discurso que envolve a proteção de pessoas no próprio uso da inteligência artificial - sendo certo que a proteção de seus interesses nacionais, de igual forma, interessa a todos que visam à elaboração de uma legislação global efetivamente pluralista e multicultural.

Parte-se, assim, de um ponto vista contra-hegemônico² quanto à inserção das tecnologias em ambiente interno, e, ademais, atenta-se às problemáticas trazidas pelos históricos mundiais de vícios em algoritmos, que, por vezes, atuam de maneira opressora em relação àqueles cidadãos situados à margem da sociedade de risco.

Para fins da presente pesquisa, aponta-se como epistemologias do sul as reflexões gerais que não incidem sobre conhecimentos em abstrato, mas em práticas de conhecimento que levem em consideração os efeitos de eventos fáticos como o colonialismo que, conforme definição de Boaventura de Souza Santos (In: SANTOS \& MENEZES 2010, p. 13), para além de todas as dominações por que é conhecido, "foi também uma dominação epistemológica, uma relação extremamente desigual entre saberes que conduziu à supressão de muitas formas de saber próprias dos povos e nações colonizados, relegando muitos outros saberes para um espaço de subalternidade". Deste modo, adotar uma percepção "sob a ótica das epistemologias do sul" consiste, ao fim e ao cabo, analisar o objeto de estudo considerando as narrativas que ecoam também de países periféricos e situados no sul global e que, tanto quanto os demais, aspiram por participação nas discussões que envolvem problemas de ordem global, tal como é o tema do acesso e do uso da inteligência artificial e do tratamento de dados pessoais em patamar mundial.

2 De pronto, salienta-se que a adoção de uma visão "contra-hegemônica" se deve à consideração, neste trabalho, de que a percepção tida como "hegemônica", acerca do tema, é aquela que tende a definir como polos ou centros de discussão sobre inteligência artificial e tratamento de dados nos Estados Unidos e nos países que compõem a União Europeia, que não sejam recentes as discussões sobre tais disciplinas (como em países latino-americanos e situados no sul global). A título exemplificativo, menciona-se que o Brasil, desde 1980, apresenta elaborações normativas que fazem expressa menção a bancos de dados automatizados e ao avanço informático, como no Projeto de Lei $n^{\circ} 2.796$, de 04 de novembro de 1980 disponível em: https://www.camara.leg.br/proposicoesWeb/prop_mostrarintegra;jsessionid=FBF15270DD557906FEB1829EFEA68AED.proposico esWeb1 ?codteor=1172300\&filename=Avulso+-PL+2796/1980. Acesso em: 27/09/2021. 
É manifesta a necessidade atual de se lograr interpretações quanto à expressão de qualquer violência ou vulnerabilidade digital ou tecnológica que se possa criar ou desenvolver - sobretudo, por meio de visões epistemológicas distintas das europeias - o que ora se propõe, sem que se intencione repudiar a visão macroscópica, dadas as possibilidades de exposição de dados pessoais por aqueles que os detém, em prejuízo daqueles que os dispõem.

A noção hodierna acerca da universalidade dos direitos humanos leva a crer que a sua efetivação depende, de fato, das teorias universais e dos órgãos protecionistas de abrangência global para que seja possível tecer análises eficientes acerca da genealogia e da manifestação e violações. Este pensar está ligado à reiterada recorrência às epistemologias europeias e norte-americanas para se pensar em ações preventivas voltadas às transgressões e violências - inclusive, àquelas voltadas ao ciberespaço. A presente investigação, no entanto, pretende olhar a problemática que envolve as discussões sobre inteligência artificial, a partir de um viés decolonizante ${ }^{3}$.

Socialmente, justifica-se a presente pesquisa pelo potencial de afirmar a existência e o fortalecimento de uma visão multicultural e pluralista da utilização de inteligência artificial e programação de algoritmos enquanto ferramentas passíveis de promover a melhora do bem-estar econômico e social dentro dos estados, como maneira de integração para análise da elaboração de regras globais, sobretudo, aquelas em desenvolvimento pela UNESCO.

Não se vislumbra superar as teorias universalistas de direitos humanos, de protecionismo de dados pessoais, tampouco a ideia de que a elaboração de regras globais voltadas à inteligência artificial e suas respectivas implicações estatais não se tratam de matéria de estudos epistemológicos globais. Visa, sim, apontar o estudo baseado nas epistemologias do sul como uma alternativa e, simultaneamente, como um meio possível de análise de recomendações sobre o uso da inteligência artificial, a fim de averiguar os seus efeitos em âmbito interno e os fenômenos decorrentes de sua efetiva implicação.

Além disso, destaca-se pertinência da visão sociocriminológica distante das epistemologias europeias acerca do fenômeno da expansão do uso da inteligência artificial pelo globo e, bem assim, das discussões sobre o tema, visando atingir resultados aplicáveis que abranjam, inclusive, a contribuição dada por países que não ocupam o centro das narrativas hoje difundidas em maior escala. A adoção dessa teoria, em um momento contemporâneo em que a globalização, por vezes, silencia ou reprime problemas regionais voltados ao ciberespaço, pode, inclusive, evidenciar uma não dicotomia entre o global e o local, cada vez mais simultâneos.

Em um primeiro momento, portanto, será analisado o panorama atual da expansão da inteligência artificial e de discussões a ela diretamente vinculadas, como é o caso do desenvolvimento legislativo em favor da proteção de dados pessoais em sentido global. Ainda, buscam-se demonstrar as narrativas sobre o tema em desenvolvimento, sobretudo, aquelas relacionadas aos riscos e desafios advindos do uso das tecnologias em questão.

Posteriormente, pretende-se realizar uma breve avaliação crítica dos esforços em andamento para a elaboração de recomendações globais para o bom uso da inteligência artificial, partindo-se de um olhar multicultural e pluralista, tendo em vista ser este o cunho dado às discussões então traçadas no âmbito de atuação das Nações Unidas. Busca-se, então, pensar as exigências e necessidades impostas pela tecnologia, neste caso, consubstanciadas na inteligência artificial, a partir da teoria das epistemologias do sul.

Por fim, pretende-se analisar qual o papel atualmente desenvolvido pela UNESCO na elaboração de uma Legislação Global sobre inteligência artificial, mensurando quais são os limites e obstáculos da sua atuação e, sobretudo, avaliando a existência ou não de força normativa ou vinculante das regras que se pretende desenvolver em âmbito internacional. Apontar-se-á, portanto, quais serão as implicações práticas nos Estados-Nação a partir desta movimentação que, atualmente, conta com o envolvimento de vinte e quatro especialistas de diferentes partes do mundo.

Assim, o estudo, através da revisão bibliográfica e da adoção de um método de abordagem dialético, pretende demonstrar, dentro das possibilidades impostas pelo objeto que está ainda em construção, quais são

\footnotetext{
O termo decolonizante faz referência à filosofia da libertação de Enrique Dussel, bem como do giro decolonial, cunhado originalmente por Nelso Maldonado Torres, que versa sobre o movimento de resistência teórico e prático, político e epistêmico, à lógica da modernidade, tratando-se, assim de uma intervenção contra à colonialidade e seus efeitos. Segundo Ballestrin: "Basicamente, a decolonização é um diagnóstico e um prognóstico afastado e não reivindicado pelo mainstream do pós-colonialismo, envolvendo diversas dimensões relacionadas com a colonialidade do ser, saber e poder. Ainda que assuma a influência do pós-colonialismo, o Grupo Modernidade/Colonialidade recusa o pertencimento e a filiação a essa corrente. O mesmo se aplica às outras influências recebidas que possibilitaram o surgimento e o desenvolvimento da construção teórica do grupo. Contudo aquilo que é original dos estudos decoloniais parece estar mais relacionado com as novas lentes colocadas sobre velhos problemas latino-americanos do que com o elenco desses problemas em si." (BALLESTRIN, 2013).
} 
as problemáticas e os benefícios postos pela Legislação Global de Inteligência Artificial em desenvolvimento pela UNESCO, objetivando, ainda, avaliar quais são seus limites e possibilidade de atuação frente ao tema para viabilizar maior grau de pluralidade nas discussões traçadas em ambiente internacional na contemporaneidade.

\section{O uso da inteligência artificial e o direito à proteção de dados pessoais: expansão global, riscos e desafios}

A inteligência artificial foi projetada, inicialmente, para simular as mais diversas faculdades da inteligência (humana, animal, vegetal, social ou filogenética) através da utilização de máquinas. Trata-se de uma disciplina científica criada oficialmente em 1956 pelos pesquisadores McCarthy, Marvin Minsky, Nathaniel Rochester e Claude Shannon - na Universidade de Dartmouth, em New Hampshire (EUA) -, tendo base na suposição de que funções cognitivas podem ser descritas com precisão e reproduzidas, tais como aprendizagem, percepção e memorização. Desde então, a inteligência artificial passou por transformações, desde o desenvolvimento de algoritmos de machine learning (aprendizagem automática ou aprendizado de máquina), passando pela conjunção com robótica e chatbots na década de 1990, até a exploração de bancos de dados automatizados (GANASCIA, 2018, p. 2).

A inteligência artificial na ciência de dados está relacionada com a compreensão que se tem a respeito do contexto político e social abrangente no qual o big data - bem como sua procedência e suas implicações - estão situadas. Isto, aliás, está diretamente vinculado à capacidade que se tem de se verificar os valores humanos tácitos, o desenvolvimento da política e o próprio poder incorporado ao big data ${ }^{4}$ e suas aplicações provenientes da inteligência artificial (FORNASIER, 2018, p. 121). Percebe-se, assim, que são muitos os elementos inseridos em um Estado-Nação capazes de contribuir para a definição e atuação das tecnologias em cada local - de forma a evidenciar que o problema ora tratado é de ordem glocals.

Diante disso é que, em tempos de big data, importa averiguar quais são os limites efetivamente impostos pelos Estados-Nação às formas de exercício arbitrário de poderes quando diante de situações que envolvem o tratamento de dados pessoais e o uso de novas tecnologias. Percebe-se, pois, a crescente inquietação com as condições de uso das tecnologias em conformidade com padrões éticos e limites impostos pela legalidade.

Com a expansão global do uso da tecnologia, emerge, também, conjuntamente, a preocupação com os meios disponíveis para elaboração de garantias que protejam direitos fundamentais que com ela se relacionem, como é o caso, evidentemente, da proteção de dados pessoais. Este direito, aliás, em âmbito interno brasileiro, já possui expressas garantias legislativas advindas da LGPD, sendo que a Suprema Corte, antes mesmo de sua entrada em vigência, já havia feito expressa referência ao direito fundamental à proteção de dados pessoais e à autodeterminação informativa'.

Em relação à normatização do direito à proteção de dados de quarta geração, conforme aponta a Comissão Nacional da informática e Liberdades Civis da França - $\mathrm{CNIL}^{7}$, verifica-se, ainda, contínuo desenvolvimento e evolução, sendo visível o avanço legislativo em inúmeras partes do globo. A Comissão divulgou, em 19/11/2019, um mapeamento deste avanço em âmbito global, posteriormente atualizado em 23/11/2021. Abaixo, figura dos mapas publicados pela Comissão:

4 De acordo com o professor José Carlos Cavalcante, o conceito de big data se aplica a informações que, por possuírem características como volume, variedade e velocidade não podem ser processadas ou analisadas através de meios tradicionais de leitura de dados (in: MAGRINI, 2019, p. 23).

5 O termo glocal foi cunhado por Roland Robertson (1992) para indicar que o local e global não excluem um ao outro; pelo contrario, se complementam ao passo que o local deve ser tido, em certo nível, como um meio de compreensão do global; e a globalização, por sua vez, compreender um encontro de localismos.

6 O Supremo Tribunal Federal (STF) reconheceu o direito fundamental à proteção de dados pessoais ao referendar a decisão liminar deferida pela Min. Relatora Rosa Weber, nos autos da ADI n 6.387/DF, datada de 24 de abril de 2020, na qual se acentuou o direito à autodeterminação informativa. O plenário da Suprema Corte suspendeu a aplicabilidade da Medida Provisória $n^{\circ}$ 954/2018, ao julgar conjuntamente as Ações Diretas de Inconstitucionalidade $n^{\circ}$ s 6387, 6388, 6389, 6393 e 6390, impedindo, assim, o compartilhamento de dados não anonimizados de telefonia fixa e móvel, por companhias de telefonia, além do endereço dos consumidores, entre as companhias de telefonia e o IBGE - Fundação Instituto Brasileiro de Geografia e Estatística.

7 Commission Nationale de l'Informatique et des Libertés. Disponível no website institucional: https://www.cnil.fr/en/data-protection-around-the-world onde as legendas podem ser acessadas de maneira interativa, com acesso às informações relacionadas com cada país. Acesso em 20 de outubro de 2020 . 
Figura 1 - Mapas Data protection around the world
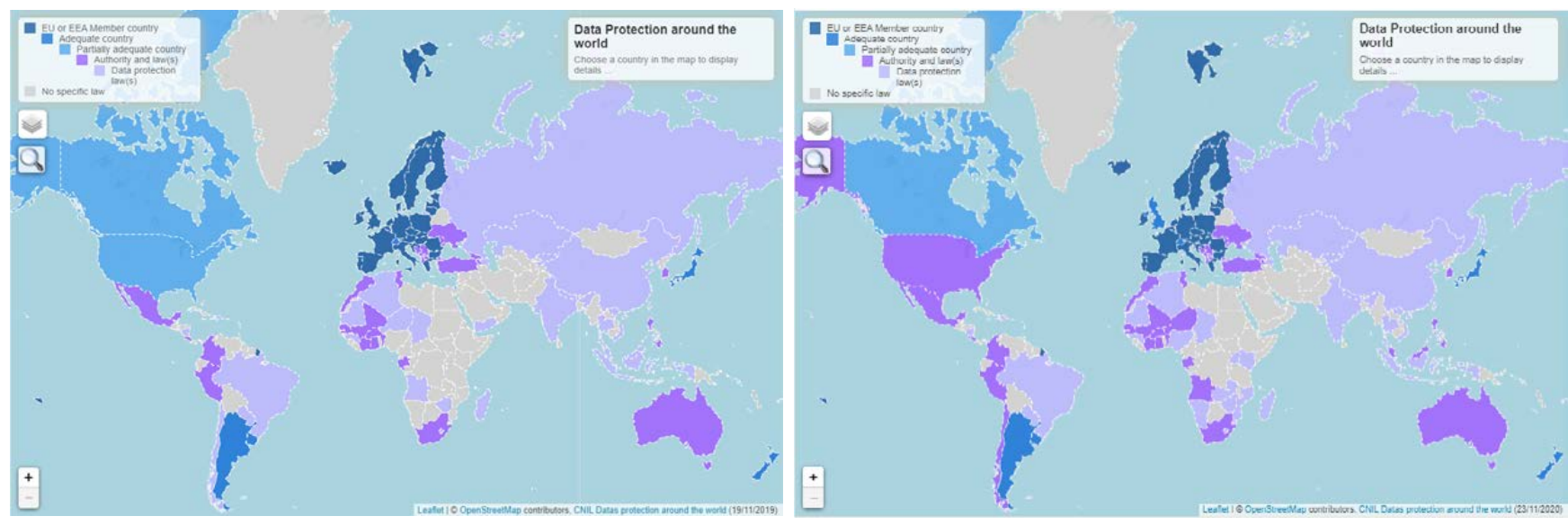

Fonte: Comissão Nacional da Informática e Liberdades Civis da França, 2019 e 2020.

Dos mapas divulgados a partir do levantamento realizado pela CNIL, depreende-se que o nível de desenvolvimento legislativo sobre a disciplina da proteção de dados ao redor do globo está em pleno avanço, eis que todos os países que apresentam no mapa grifos azuis e roxos já possuem, em diferentes níveis de adequação e implementação, e dentro de seus ordenamentos internos, regras que incluam garantias de não lesão à proteção de dados.

Tal expansão decorre do fato de que a atividade de tratamento de dados pessoais, seja pelo Estado, seja pelo setor privado, segundo Doneda (2019, p. 24), demanda a:

construção de instrumentos que a harmonize com os parâmetros de proteção da pessoa humana presentes nos direitos fundamentais e funcionalizados por instrumentos regulatórios que possibilitem aos cidadãos um efetivo controle em relação aos seus dados pessoais, garantindo o acesso, a veracidade, a segurança, o conhecimento da finalidade para a qual serão utilizados, entre tantas outras garantias que se fazem cada vez mais necessárias.

Diante desta visível preocupação global com a elaboração normativa relacionada à proteção de dados e, atrelada a isso, o intento de se construir um rol de recomendações que auxilia na prática ética do uso da inteligência artificials $^{8}$, percebe-se que, de forma substancial, a sociedade internacional compartilha de problemas e inquietações comuns. Precisamente por esta razão, também, é que o desenvolvimento das discussões e as construções de narrativas devem se dar em âmbito expandido, inclusivo e multicultural.

A sociedade internacional, afinal, possui mais problemas comuns do que interesses nacionais, porquanto no processo de globalização, passou-se a compartilhar de fronteiras mais flexíveis, de forma que os Estados tendem a encontrar uma dificuldade mais elevada para o tratamento de problemas globais de maneira isolada. Por isto, tem-se a necessidade de fortalecimento da sociedade civil transnacional, sobretudo, porque o Estado-Nação, na modernidade, não é dotado de meios suficientes à resolução das problemáticas comuns da humanidade em âmbito global. (MIRANDA \& CADEMARTORI, 2018, p. 16). E este, certamente, é o caso do desenvolvimento de regras legislativas, de ordem global e efetivamente aplicáveis em âmbito interno dos Estados-Nação, sobre inteligência artificial em acelerada expansão.

Para além das considerações sobre a existência de uma problemática que envolve o pensar nos limites da atuação da inteligência artificial em âmbito de poderes estatais dentro dos Estados-Nação cumpre avaliar, criticamente, as narrativas em desenvolvimento relacionadas aos riscos advindos de sua expansão.

De pronto, cumpre mencionar que o risco de constituição de uma vulnerabilidade digital humana decorrente da fragilidade da proteção dos dados pessoais em decorrência do uso da inteligência artificial, certamente, se trata

8 De forma a exemplificar a atenção dada ao tema pelo Brasil, em âmbito interno, faz-se menção ao Projeto de Lei $n^{\circ} 21 / 2020$, aprovado pela Câmara de Deputados no dia 06/07/2021 e ainda em plena tramitação, que tem o objeto precípuo de criar o marco legal do desenvolvimento e do uso da Inteligência Artificial (IA) pelo poder público, por empresas, entidades diversas e pessoas físicas. Disponível em: <https://www.camara.leg.br/ proposicoesWeb/prop_mostrarintegra?codteor=1853928>. Acesso em 29/09/2021. 
de hipótese que assola a comunidade internacional e - justamente por isso - tem-se, atualmente, uma reunião de esforços para elaboração normativa em sentido - interno e externo - para garantia de dados pessoais. Entretanto, além deste risco evidente, há outros relacionados com as condições éticas do uso em questão.

Segundo Ganascia (2018, p. 2), um dos elementos que representa, hoje, um preocupante risco ético do uso da inteligência artificial é a constatação de que as máquinas têm excedido as capacidades cognitivas humanas em diversas áreas, de forma que este risco pode ensejar a escassez de trabalho, a limitação da autonomia pessoal humana e, sobretudo, incidentes relacionados à liberdade e à segurança. Ressalva, entretanto, que sua autonomia é puramente tecnológica - e não moral - de maneira que não representa uma ameaça existencial para humanidade.

A Diretora-Geral da UNESCO, Audrey Azoulay (2018, p. 2), assevera que a inteligência artificial consiste em ferramenta capaz de oportunizar o alcance de objetivos estipulados pela Organização na Agenda 2030. Por outro lado, pensa-se que o auxílio na aceleração de determinadas atividades representa uma ameaça, ao passo que a automação e a digitalização criam situações de desigualdade, provocando a diminuição da diversidade cultural, interferindo no mercado de trabalho, criando inseguranças empregatícias, aumentando disparidades entre aqueles que possuem acesso às tecnologias e aqueles que são delas privados.

Audrey Azoulay (2018, p. 2) aponta, ainda, que a UNESCO, em reunião de esforços com Comissão Mundial para a Ética do Conhecimento Científico e Tecnológico (COMEST) e o Comitê Internacional de Bioética (IBC), assume a responsabilidade de:

liderar um debate universal e esclarecido - não um debate técnico, mas um debate ético - de modo a entrar nesta nova era de olhos bem abertos, sem sacrificar valores, e tornar possível o estabelecimento de uma estrutura global comum de princípios éticos, caso seja a vontade dos Estados-membros.

Diante disso, faz-se imprescindível compreender e avaliar o nível de atuação hoje desempenhado pela Organização para a manutenção deste debate em espaço internacional.

\section{Os esforços em andamento para elaboração de regras globais para o uso ético da inteligência artificial: a Legislação Global de Inteligência Artificial em construção pela UNESCO sob uma perspectiva multicultural e pluralista}

Recentemente, a Diretora Geral da UNESCO, Audrey Azoulay (2018, p. 1), explicitou que a expansão da inteligência artificial tende a transformar a vida humana de maneira inimaginável, aferindo que esta transformação, atualmente, já afeta de forma direta a sociedade. Diante de tal constatação, Azoulay afirma que a UNESCO possui um importante papel nesta mudança: primeiro, porque o uso da inteligência afeta as especialidades da Organização como um todo; e segundo, porque causará efetiva transformação na educação, através das modificações relacionadas a ferramentas de ensino, métodos de aprendizado, acesso e treinamento docentes. Aponta, por fim, direta interferência da inteligência artificial no setor cultural, através, por exemplo, da tecnologia 3D para reconstrução de patrimônio cultural - o que, aliás, está em desenvolvimento na cidade de Mossul, no Iraque .

Nesse ínterim, cumpre avaliar que houve um aumento considerável da pesquisa que avança sobre no campo técnico da inteligência artificial. Assim, e ainda a respeito disso, Azoulay (2018, p. 1) afere que, em que pese esta seja objeto de investigação científica, mesmo que a ética de sua aplicação não venha a ser. Precisamente por isso, a Diretora afirma que é responsabilidade da UNESCO "liderar um debate universal e esclarecido de modo a entrar nesta nova era de olhos bem abertos, sem sacrificar nossos valores, e tornar possível o estabelecimento de uma estrutura mundial comum de princípios éticos".

\footnotetext{
A cidade iraquiana Mossul será reconstruída a partir de um projeto intitulado The 5 Farming Bridges, de autoria do arquiteto Vincent Callebaut, que propôs a construção de cinco pontes agrícolas, cujas estruturas serão produzidas a partir de tecnologia de impressa 3D. Frisa-se que a matériaprima utilizada para a impressão será, precisamente, os próprios escombros da guerra.
} 
Diante desta preocupação, é que a UNESCO deu início à elaboração do Primeiro instrumento mundial de definição de padrões sobre a ética da inteligência artificial $(I A)^{10}$, cuja elaboração decorre de decisão tomada pela Organização durante a 40ª sessão da Conferência Geral da Organização, em novembro de 2019"1.

Para início do projeto, a UNESCO contou com a assistência de especialistas ad hoc, que elaboraram um documento contendo recomendações para uso da inteligência artificial, intitulado Preliminary Study on the Ethics of Artificial Intelligence. Em seguida, elaborou-se o instrumento cunhado First Draft of the Recommendation' dando início às fases de consultas públicas inclusivas e multidisciplinares para desenvolvimento do instrumento. Percebe-se que a Organização primou, desde o princípio, pela participação coletiva para desenvolvimento do documento, visando a adoção de cunho pluralista e multicultural.

$\mathrm{O}$ anteprojeto da recomendação sobre a ética da inteligência artificial ${ }^{13}$ aponta, preambularmente, que, em conformidade com a decisão tomada na $40^{\text {a }}$ Conferência-Geral (Resolução $n^{\circ} 40 \mathrm{C} / 37$ ), em março de 2020 , o Grupo Especial de Experts (GEE) construiu o documento, ainda que em situação de adaptação às novas condições impostas pela pandemia de Covid-19, o que demandou que o grupo trabalhasse de maneira virtual/remota.

Narrou-se, no documento, que entre os meses de junho e agosto de 2020 , foi efetivado um amplo processo de consulta com múltiplas partes interessadas na primeira versão da recomendação. A consulta pública realizada: (a) contou com mais de 800 (oitocentas) respostas; (b) foram virtuais, regionais e sub-regionais, organizadas conjuntamente com os países e instituições anfitriãs em todas as regiões de abrangência da UNESCO, contando com mais de 500 participantes; (c) incluiu a realização de workshops abertos, organizados por parceiros, para deliberação de múltiplos stakeholders e cidadãos, com cerca de 500 participantes. Informou-se que o processo de consulta gerou mais de 50.000 comentários ao texto, durante a elaboração.

Disto, percebe-se, com clareza, que a Organização visou, já no princípio do desenvolvimento do rol de recomendações, a incorporação de uma visão participativa, e abrangente. Preocupou-se, desde a elaboração do escopo do documento, com uma incursão no tema da inteligência artificial, a partir da adoção de um olhar contra-hegemônico, para desenvolvimento de uma definição de condutas tidas como éticas e de boas práticas, construídas pelo maior número possível de interessados.

A postura adotada pela Organização demonstra que, em sentido global, há preocupação relacionada à necessária fragmentação da então sedimentada centralização das narrativas sobre inteligência artificial, nos polos consistentes nos Estados Unidos da América e na União Europeia. Afinal, a título de exemplo, como bem observa o cientista e especialista sul-africano Marwala (2019), atualmente, países da África estão sob efeito da Quarta Revolução Industrial $\left(4 \mathrm{R}^{14}\right)$ e devem fazer uso da tecnologia para impulsionar melhorias econômicas internas no continente.

Tais situações fáticas de crescimento e expansão da inteligência artificial em países que não compunham, até então, as localidades tidas como polos de discussão central do tema, evidentemente, foram consideradas pela Organização durante a elaboração do instrumento em desenvolvimento para fixação de recomendações, afinal, favoreceu-se a ampla participação durante o processo.

10 O instrumento em elaboração foi assim definido pela UNESCO em seu website institucional que, entretanto, a depender a matéria veiculada, por vezes o intitula Legislação Global de Inteligência Artificial. Definição disponível em: <https://pt.unesco.org/news/consulta-online-primeira-versao-darecomendacao-etica-da-inteligencia-artificial>. Acesso em 28 de outubro de 2020. Por fim, cumpre salientar que, no documento oficial disponibilizado pelo grupo de especialistas ad hoc mencionado pela diretora geral, o instrumento foi definido como Recommendation on the Ethics of Artificial Intelligence.

11 A UNESCO reúne, a cada dois anos, os 193 Estados-Membros para uma conferência geral, na qual se determinam o programa e o orçamento da Organização. Em 2019, a conferência ocorreu em novembro, em Paris, na França, e fez-se constar na agenda oficial do Ministério das Relações Exteriores do país, conforme informação institucional do Itamaraty disponível em: http://www.itamaraty.gov.br/pt-BR/notas-a-imprensa/21085calendario-de-eventos-entre-15-e-22-de-novembro-de-2019. Acesso em 28 de outubro de 2020.

12 Disponibilizado pela Organização em seu website institucional, contendo tradução em seis línguas, para consulta online, disponível em: https:// unesdoc.unesco.org/ark:/48223/pf0000373434. Acesso em 28 outubro de 2020.

13 O Anteprojeto de recomendação sobre a ética da inteligência artificial, realizado pelo Grupo Especial de Experts (GEE) encarregado de elaborar um projeto de recomendações sobre a ética da inteligência artificial, foi disponibilizado pela UNESCO em seu website institucional oficial em 07 de setembro de 2020. Disponível em: <https://unesdoc.unesco.org/ark:/48223/pf0000373434_spa?posInSet=2\&queryld=130283e0-c962-4358-857b46ba99a8d67b>. Acesso em 28 de outubro de2020.

14 A Quarta Revolução Industrial (4RI) é impulsionada por tecnologias emergentes, baseadas na combinação de inovações digitais, biológicas e físicas Essas tecnologias mais recentes, que estão mudando o modo como vivemos e trabalhamos, incluem a inteligência artificial (IA) e a robótica, a internet das coisas, realidade aumentada, computação quântica, impressão 3D, blockchain, manufatura aditiva, neurotecnologias, geoengenharia, e edição de genoma. (OVANESSOFF \& PLASTINO, 2017) 
É possível avaliar, em certa medida, que a postura adotada está em conformidade com uma atuação voltada ao desenvolvimento de ações que visam uma construção decolonial, pautada nas epistemologias do sul, no que diz respeito à integração de perspectivas e contribuições distintas daquelas advindas dos Estados Unidos e dos países que compõem a União Europeia. Assim, tem-se em vista seu interesse em considerar a problemática que envolve a concentração de narrativas relativas a temas que, por certo, são de interesse global - como é o caso da inteligência artificial e da regulação sobre as suas respectivas maneiras de uso.

Ao se adotar uma postura contra-hegemônica - isto é, uma postura inclusiva das narrativas, percepções e contribuições advindas de países situados no sul global acerca do tema, que, diga-se, é de interesse global comum - e com vista à participação multicultural, é possível que se afira, neste caso, maior êxito na elaboração de textos legislativos, sobretudo, porque os resultados obtidos de uma ampla participação para realização do estudo e construção do documento estarão essencialmente ligados à análise de dados colhidos junto de um rol de países mais amplo e diferenciado - isto é, detentor de idiossincrasias outras que merecem a devida atenção - e que, por sua vez, consistem, também, em dados regionalizados, que denotam especificidades locais igualmente importantes para o desenvolvimento de regras ou recomendações voltadas ao cumprimento global.

Afinal, é bastante provável que eventual realização da mesma análise, partindo-se apenas com vista ao panorama atual ocidental, não cumprisse os objetivos de consulta inicialmente formulados e não desse ensejo ao anteprojeto amplo que considerou, expressamente: a Declaração Universal de Direitos Humanos (1948), a Convenção Internacional sobre a Eliminação de Todas as Formas de Discriminação Racial (1965), o Pacto Internacional de Direito Civis e Políticos (1966), o Pacto Internacional de Direitos Econômicos, Sociais e Culturais (1966), a Convenção sobre a Eliminação de Todas as Formação de Discriminação contra a Mulher (1979), Convenção sobre os Direitos das Pessoas com Deficiência (2006), Convenção sobre a Proteção e Promoção da Diversidade das Expressões Culturais (2005), a Declaração das Nações Unidas sobre os Direitos dos Povos Indígenas (2007), dentre outros.

Estas considerações tecidas no início do documento desenvolvido reforçam que os fenômenos do avanço tecnológico, da datatificação ${ }^{15}$, do dataísmo ${ }^{16} \mathrm{e}$ de inúmeras práticas humanas e do uso da inteligência artificial não precisam ser pensados a partir de teses realizadas com vista a problemáticas que assolam os países centrais. Isso porque, mesmo aos países situados em localidades periféricas, por certo, interessam os rumos das regras desenvolvidas sobre o assunto - seja porque farão uso da tecnologia para alavancar suas situações socioeconômicas, seja porque sofrerão, em certa medida, consequências advindas destas decisões.

É indispensável considerar, do ponto de vista global, que as inúmeras localidades que se interessam, diretamente, pelos resultados do instrumento em andamento apresentam notável hibridez cultural, dada a herança do colonialismo plural, muitas vezes, somada à questão indígena e à escravidão. Neste complexo contexto, é que (re)pensar os direitos humanos desde a heterogeneidade se demonstra uma tarefa árdua, mas possível, inclusive, quando o objeto de análise inclui elementos tecnológicos, voláteis e em contínua expansão.

A primazia pela adoção de uma postura multicultural e pluralista evidencia, também, a viabilidade de se analisar o fenômeno de expansão global da inteligência artificial partindo-se de um ponto de vista do espaço geográfico. Isso a fim de buscar observar a necessidade de desenvolvimento de regras, orientações e/ou recomendações globais que tenham como base a perspectiva de que cada forma de geografia é representativa de um modo de produção ou de um de seus momentos, dadas as peculiaridades econômicas, sociais, culturais e políticas de determinado local e período.

Neste passo, cumpre esclarecer que, ao se apontar para aspectos geográficos ${ }^{17}$, não se olvida que o advento do uso da inteligência artificial e a preocupação com as regras relativas a direitos de não lesão ao direito à proteção de dados pessoais sejam objetos de análise e de preocupação comum global, sem que existam necessárias barreiras geográficas entre países e continentes quando se está diante de atividades como a transferência internacional de

15 Trata-se de um movimento de transformação das ações humanas para tecnologia, no sentido de automatizá-las ou digitaliza-las. Termo utilizado pelos autores Stefania Milan e Emiliano Trerè (2019) ao abordar o data sul.

16 Conforme ensina Yuval Harari, segundo o dataísmo, o Universo consiste num fluxo de dados e o valor de qualquer fenômeno ou entidade é determinado por sua contribuição ao processamento de dados (2015, p. 374).

17 A este respeito, aliás, referencia-se o apontamento feito por Manuel Castells (2001, p. 4) acerca do aparente paradoxo trazido pelos aspectos geográficos: muito se pensava sobre a Internet e as tecnologias contribuírem para o desaparecimento de cidades, tendo em vista a possibilidade de trabalho remoto em ambientes afastados. Contudo, o que se nota com o avançar dos tempos é a maior centralização de pessoas em grandes polos de concentração e transferência de dados e informações - o que demonstra, evidentemente, que as novas tecnologias tendem a influenciar circunstâncias vinculadas à geografia. 
dados e o desenvolvimento de bens de consumo inteligentes. Ocorre, contudo, que, quando se falar sobre a efetiva consideração de perspectivas e de contribuições locais de países periféricos durante os processos legislativos para elaboração de normas e regras sobre o tema, em sentido supraconstitucional, os países do sul global têm adotado uma posição de subalternidade - seja por questões sociais, seja por questões históricas, vinculadas ao colonialismo.

Quando a geografia passa a pretender enxergar o espaço humano como um fato histórico, como ele é e conforme deve ocorrer, a história da sociedade mundial, devidamente aliada à sociedade local, pode servir como um fundamento à compreensão da realidade espacial e permitir a sua transformação a serviço do ser humano. Assim, importante se faz que a história seja escrita a partir de um determinado espaço e não à margem dele, eis que não se vislumbra a possibilidade de uma sociedade a-espacial.

Tem-se que o espaço é social e, neste sentido, Santos (1977, p. 37) questiona se é possível falar de formação econômica e social sem incluir a categoria do espaço, argumentando que esta se trata, de fato, de uma categoria de formação econômica, social e espacial, mais do que uma simples formação econômica e social, como interpretada até hoje.

Entretanto, ressalta-se que não há, aqui, a intenção de justificar situações de exclusão ou restrição de países durante o desenvolvimento de narrativas, instrumentos, ações ou atuações relacionadas à inteligência artificial, unicamente, a partir da constatação de presença de subdesenvolvimento econômico local. Não se busca ligar, exclusivamente, a questões socioeconômicas toda manifestação de ausência de inclusão ou de ocidentalismo em espaço global, mas, sim, à totalidade de peculiaridades e características que compõem os países do sul ou, ainda, aqueles que diferem dos polos centrais de discussões sobre o tema.

A unidade da continuidade e da descontinuidade do processo histórico de evolução e de alastramento da tecnologia não pode ser realizada senão no espaço social e, também, geográfico. Isso porque, tanto a evolução da formação social, quanto o desencadeamento da inteligência artificial em determinado âmbito social, estão intimamente condicionadas pela organização do espaço, dependendo, sobretudo, da formação social atual em que se encontram.

Por esta razão e, também, considerando que a adoção de tecnologias envolve, hoje, o conjunto estabelecimento de garantias que promovam a proteção de dados pessoais - direito este fundamental - buscando-se, assim, um meio de complementação das teorias protecionistas universalistas de direitos humanos, para a idealização de uma teoria voltada para o local onde são tratados os dados pessoais e efetivamente utilizada a inteligência artificial.

Ademais, busca-se, no projeto decolonial, a criação de uma ligação entre os povos colonizados - ou os que sofrem seus efeitos - e o restante da sociedade global, especialmente, a partir da transmodernidade idealizada por Enrique Dussel. Em sua filosofia, Dussel propõe que se vá além das considerações epistêmicas europeias atuais, a fim de que se enfrente a modernidade eurocentrada através de uma multiplicidade de respostas críticas decoloniais que partam do sul global. Frisa-se, ainda, que ao tratar de sul global, não se faz referência apenas àqueles situados geograficamente ao Sul, mas a todos cujos poços e culturas foram subalternizados pelo projeto eurocêntrico da modernidade (GROSFOGUEL, 2010).

Neste ponto, ressalta-se que a utilização do termo decolonial e não descolonia decorre do sentido de continuidade implícito no termo adotado. Acerca disso, Walsh (2009, p. 18) aclara que:

Suprimir a letra "s" e nomear "decolonial" não é promover um anglicismo. Pelo contrário, é marcar uma distinção do significado em castelhano "de" e "des". Não pretendemos simplesmente desfazer ou reverter o colonialismo; isto é, passar de um momento colonial para um não colonial, como se fosse possível que seus padrões e pegadas deixassem de existir. A intensão é pontuar e provocar um posicionamento - uma postura e atitude contínua - de transgredir, intervir, insurgir e incidir. $\mathrm{O}$ decolonialismo denota, então, um caminho de luta contínua na qual podemos identificar, visibilizar e encorajar lugares de exterioridade e construções alternativas. (tradução nossa)

Já no tocante aos estudos sobre a colonialidade e, especificamente, sobre o decolonialismo, Grosfoguel e Mignolo (2008, p. 31) o mencionam como uma opção política que pode ser definida da seguinte maneira:

...Cuando decimos 'decolonialidad' (...) estamos significando un tipo de actividad (pensamiento, giro, opción), de enfrentamiento a la retórica de la modernidad y la lógica de la colonialidad. Ese enfrentamiento no es sólo resistencia sino re-existencia, (...). Pensar descolonialmente, habitar el giro descolonial, 
trabajar en la opción descolonial (entendida en su singular perfil aunque manifiesta en variadas formas según las historias locales), significa entonces embarcarse en un proceso de desprenderse de las bases eurocentradas del conocimiento (tal como lo explica Aníbal Quijano) y de pensar haciendo-conocimientos que iluminen las zonas oscuras y los silencios producidos por una forma de saber y conocer cuyo horizonte de vida fue constituyéndose en la imperialidad (según el concepto del británico David Slater).

Diante de tais constatações, portanto, é que se tem por benéfica a adoção de uma análise do fenômeno de expansão da inteligência artificial e seus efeitos sob o olhar de uma teoria contra-hegemônica, tendo em vista a imprescindibilidade de se considerar estudos e autores voltados à ideia de decolonização e adoção de epistemologias do sul para promoção de ações e atuações voltadas ao desenvolvimento de projetos pluralistas e multiculturais sobre o tema.

É imprescindível, pois, a presença do multiculturalismo e da perspectiva do sul ao se abordar tais construções, a fim de se evitar o movimento cunhado por Boaventura (2010) como epistemicídio - isto é - a supressão dos conhecimentos locais a pretexto de uma missão colonizadora ou homogeinizadora, reduzindo-se a diversidade epistemológica, cultural e política do sistema mundial.

\section{Rol de recomendações para uso ético da IA: das implicações práticas e efeitos gerais da construção normativa no sistema internacional}

A Legislação Global de Inteligência Artificial em desenvolvimento pela UNESCO, tendo já passado pela fase de consulta pública e chegado até a publicação de um anteprojeto do rol de recomendações relativo à ética de seu uso, contando com a contribuição de especialistas de diversos Estados-Nação, se trata de um instrumento normativo que trará, quando finalizado, implicações reais em âmbito internacional. A Organização busca, por intermédio desta reunião de esforços, não apenas demonstrar sua visão acerca do desenvolvimento ético da tecnologia em sentido amplo e da própria inteligência artificial, como também evidenciar a existência de referências socioculturais que precisam ser consideradas durante a elaboração de um instrumento normativo de tamanha amplitude.

O instrumento em elaboração, como já expressado, visa estabelecer um rol de recomendações para uso ético da inteligência artificial, constando em seu anteprojeto, inclusive, a existência de recomendação expressa de que os Estados-Membros apliquem as disposições constantes no rol ao adotar medidas adequadas, sobretudo, medidas legislativas ou de outra ordem que se mostre necessária, em conformidade com a prática constitucional que Ihe for correspondente, considerando suas estruturas e ordenamentos internos, a fim de dar efetividade às normas e princípios constantes no rol e em suas respectivas jurisdições.

Ainda, traz o documento a recomendação de que os Estados-Membros garantam, internamente, que as empresas do setor privado dedicadas a tecnologias de inteligência artificial assumam suas responsabilidades relacionadas aos enunciados e princípios constantes no rol de recomendações, além de promover que os usos se deem tanto em atenção à pesquisa científica sólida, quanto em atenção a uma análise e evolução ética.

Percebe-se, pois, que a então Legislação Global de Inteligência Artificial tratar-se-á, efetivamente, de um rol de recomendações - que, por sua vez, incluirá enunciados normativos e princípios relacionados ao uso da inteligência artificial -, definindo um âmbito de aplicação, finalidades, objetivos, valores e princípios, além de âmbitos de ação política, indicando análise de evolução do impacto ético, definições de governança, afirmação de uma política de dados de cooperação internacional e demonstrando, ainda, as implicações relacionadas aos temas: meio ambiente, gênero, cultura, educação, trabalho, saúde e bem-estar social.

E, sobretudo, devido o rol se estender a todos os Estados-Membros, em consonância com a proteção dos direitos humanos, das liberdades fundamentais, da dignidade humana e do respeito ao meio ambiente e aos ecossistemas, é que se deve avaliar, precisamente, quais são os seus efeitos.

Aponta-se, primeiramente, que aos Estados-Membros caberá o desenvolvimento real de políticas e atuações de cooperação para conformidade normativa interna com o rol de recomendações proposto pela Organização, especialmente, se a desconformidade representar, em qualquer nível, uma forma de violação de direitos humanos.

Nesse sentido, explicita Ramos (2013, p. 116) que a apuração de eventuais violações a direitos humanos, no âmbito das Organizações das Nações Unidas (ONU), pode ser realizada em duas áreas: (a) a convencional, que decorre de acordos internacionais dos quais os Estados-Membros são signatários; e (b) a extraconvencional, que é decorrente de resoluções da ONU e de seus órgãos, editadas a partir de interpretação da carta da Organização 
das Nações Unidas e seus dispositivos relativos à proteção dos direitos humanos. Ambas foram um sistema global de proteção de direitos humanos.

Perceptíveis, são, portanto, os efeitos do instrumento. Primeiramente, porque a aderência às recomendações definidas pela Organização, pelos Estado-Membros, tende a evitar apontamentos de eventual configuração de violação a direitos humanos vinculada à área extraconvencional, em decorrência de mau uso da inteligência artificial em âmbito interno. E em segundo lugar, pois os Estados-Nação devem promover o desenvolvimento legislativo no sentido de adequar os enunciados normativos internos às normas e princípios do rol de recomendações, além de fazerem evoluir ações políticas com esta finalidade.

Cumpre esclarecer, entretanto, que, conforme apontado por Ramos (2013, p. 356/357), a recomendação se trata de uma opinião não vinculante, advinda de um órgão internacional de direitos humanos e "fruto da existência de obrigação internacional de monitoramento e supervisão dos direitos protegidos (o chamado 'droit de régard'). Essas instâncias, enquanto atuantes no monitoramento, podem observar e sugerir apenas".

Em se tratando de um instrumento elaborado pela UNESCO, isto é, uma agência especializada do Sistema ONU, pode-se defender sua origem extraconvencional e, por conseguinte, seu caráter não vinculante. Todavia, em que pese não exista vinculação de seus termos em relação aos Estados-Membros que lhe são signatários, é de se considerar seu potencial poder de embaraço ou mobilização da vergonha. Segundo Ramos (2013, p. 357) "essas deliberações compõem o chamado 'power of embarras', que por definição é uma pressão política, já que Ihe faltaria a chamada força vinculante. Busca-se, então, a chamada 'mobilisation de la honte', para que o Estado violador, 'sponte propria', repare integralmente a ofensa aos direitos humanos protegidos".

Observa-se que a responsabilidade advinda deste instrumento tende a ser de ordem política - sem ter, como consequência, a aplicação sanção ou busca de reparação - de forma que a penalidade exequível seria aquela de ordem moral, ligada, portanto, à opinião pública mundial. Ademais, em que pese a ausência de força vinculante do rol de recomendações voltados à ética do uso da inteligência artificial, este mecanismo extraconvencial possui um efeito jurídico indireto, qual seja, a possibilidade de se utilizar o instrumento como elemento probatório para a instrução de outro procedimento de julgamento internacional de um Estado, o que - aí sim - Ihe tornaria submisso às recomendações, então, desprezadas internamente.

Desta forma, não há que se falar em inexistência de implicações práticas ou de efeitos jurídicos do rol de recomendações em construção pela UNESCO, pelo contrário. Ainda que este não possua força vinculante em razão de sua natureza de mecanismo extraconvencial, é evidente sua força de embaraço para aderência dos EstadosMembros. Ademais, seus efeitos jurídicos indiretos, seja para formação de provas de julgamento internacional, seja como material para uso político de estados e organizações internacionais, representam uma forte relevância moral potencializadora da legitimação da ação de demais entes da comunidade internacional.

\section{Considerações finais}

O crescimento e desenvolvimento das formas de uso e de aplicação da inteligência artificial em nível global, cada vez mais acelerado, evidencia a expansão da tecnologia para espaços geográficos não mais situados entre aqueles centros até então reconhecidos pela polarização das narrativas e dos ditames de sua utilização e desenvolvimento.

Diante desse cenário, justifica-se o intento agregador da UNESCO em propor a elaboração de um rol de recomendações voltado à ética no uso da inteligência artificial criado, sobretudo, a partir de um intento multicultural, abrangente, integrador e pluralista.

Sob a ótica das epistemologias do sul, sobretudo, tal ação constitui um visível avanço em termos mundiais de cooperação durante a elaboração de instrumento normativo em espaço de sistema internacional - sendo claro que elementos de consulta pública e participação de especialistas de um número considerável de Estados-Membros representam uma maturidade no discurso e na prática da construção normativa global pensada para a resolução de problemas comuns da humanidade.

Em se tratando a inteligência artificial, não apenas de um mero meio utilizado em tempos de datatificação de atividades da vida humana, mas, ademais, uma verdadeira disrupção tecnológica que tende a interpelar os limites de sua própria adequabilidade, são inúmeros os riscos e desafios que acompanham os benefícios que esta promete trazer às ocupações humanas. Precisamente por isso, todo esforço para a elaboração normativa 
vinculada a intentos de multiculturalismo e inclusão do sul global no desenvolvimento das discussões, investigações, narrativas e criações de ordem mundial é de extrema relevância.

Por fim, deve ser entendido o rol de recomendações em desenvolvimento pela UNESCO como um mecanismo extraconvencional que - embora não possua força vinculante e funcione como um conselho ou exortação - possui seus efeitos práticos e reais. É preciso que seja contornado ou, pelo menos, dirimido o sentimento de ajuridicidade desta deliberação internacional. Primeiro, por se considerar seus efeitos jurídicos indiretos; e, segundo, dada sua força para legitimação de ações de organizações e comunidades do sistema internacional no sentido de proteção de direitos humanos - força esta advinda, também, da sua própria condição de criação, pautada no pluralismo e no multiculturalismo.

Deve-se aspirar, portanto, pela maturidade dos Estados-Membros para o estabelecimento de uma prática interna, isto é, de um costume de adoção e de cumprimento destas deliberações, tanto para desenvolvimento legislativo de adequação, quanto para elaboração e efetivação de ações políticas relacionadas em âmbito interno.

\section{Referências}

AZOULAY, Audrey. Aproveitando o melhor da IA. Entrevistadora: Jasmina Sopova. O Correio da UNESCO, Paris, n. 3, p. 36-39, jul./set. 2018. Disponível em: https://unesdoc.unesco.org/ark:/48223/pf0000265211_por. Acesso em: 28 out. 2020.

CASTELLS, Manuel. Internet e la sociedad red. La Factoría, Madrid, v. 16, n. 14-15, p. 1-12, feb./sept. 2001.

DONEDA, Danilo. Da privacidade à proteção de dados pessoais: elementos da formação da Lei Geral de Proteção de Dados. 2. ed. São Paulo: Thompson Reuters Brasil, 2019.

FORNASIER, Mateus de Oliveira. Democracia e tecnologias de informação e comunicação: mídias sociais, bots, blockchain e inteligência artificial na opinião pública e na decisão política. Rio de Janeiro: Lumen Juris, 2020.

GANASCIA, Jean-Gabriel. Inteligência Artificial: entre o mito e a realidade. O Correio da UNESCO, Paris, n. 3, p. 7-9, jul./set. 2018. Disponível em: https://pt.unesco.org/courier/2018-3/inteligencia-artificial-o-mito-e-realidade. Acesso em: 28 out. 2020.

GROSFOGUEL, Ramón; MIGNOLO, Walter. Intervenciones coloniales: una breve intervención. Tabula Rasa, Bogotá, n. 9, p. 29-37, jul./dic. 2008. Disponível em: https://www.revistatabularasa.org/numero09/intervencionesdecoloniales-una-breve-introduccion/. Acesso em: 28 nov. 2021.

HARARI, Yuval Noah. Homo Deus: uma breve história do amanhã. Tradução: Paulo Geiger. Rio de Janeiro: Companhia das Letras, 2015.

MARWALA, Tshilidzi. A inteligência artificial na porta da África. Entrevistador: Edwin Naidu. O Correio da UNESCO, Paris, n. 2, p. 56-57, abr./jun. 2019. Disponível em: https://pt.unesco.org/courier/2019-2/inteligenciaartificial-na-porta-da-africa. Acesso em: 28 out. 2020.

MILAN, Stefania; TRERÉ, Emiliano. Big Data from the South(s): beyond data universalism. Television \& New Media, [s.l.], v. 20, n. 4, p. 319-335, 2019. Disponível em: https://journals.sagepub.com/doi/ full/10.1177/1527476419837739. Acesso em: 28 nov. 2021.

MIRANDA, José Alberto Antunes de; CADEMARTORI, Sérgio Urquhart. Govenança global e a sociedade internacional: mais problemas comuns do que interesses nacionais. Juris Poiesis, Rio de Janeiro, v. 21, n. 25, p. 01-20, 2018. Disponível em: http://repositorio.unilasalle.edu.br/handle/11690/1819. Acesso em: 28 nov. 2021.

OVANESSOFF, Armen; PLASTINO, Eduardo. Como a inteligência artificial pode acelerar o crescimento da América do Sul. [S.I.]: Accenture, 2017. Disponível em: https://www.accenture.com/_acnmedia/PDF-50/ Accenture-Como-a-inteligencia-artificial-acelero-crescimento-da-america-do-sul.pdf. Acesso em: 28 nov. 2021.

RAMOS, André de Carvalho. Processo internacional de direitos humanos. 3. ed. São Paulo: Saraiva, 2013. 
ROBERTSON, Roland. Globalization: social theory and global culture theory, culture \& society. London: SAGE Publications, 1992.

SANTOS, Milton. Sociedade e espaço: a formação social como teoria e como método. Boletim Paulista de Geografia, São Paulo, v. 1, n. 54, p. 81-99, jun. 1977.

SANTOS, Boaventura de Sousa; MENESES, Maria Paula. Epistemologias do sul. São Paulo: Cortez, 2010.

WALSH, Catherine; GARCÍA LINERA, Alvaro; MIGNOLO, Walter. Interculturalidad, Estado, Sociedad: luchas (de)coloniales de nuestra época. Quito: Universidad Andina Simón Bolívar : Ediciones Abya Yala, 2009.

Recebido em: 23/12/2020

Aceito em: 29/09/2021 